\title{
Fotoferese extracorpórea
}

\section{Extracorporeal photopheresis}

Márcia M. Silva ${ }^{1}$

Luis Fernando S. Bouzas²
Fotoferese extracorpórea é uma modalidade de terapia celular que tem demonstrado eficácia e segurança em pacientes portadores de doenças auto-imunes e mediadas por células T, incluindo esclerodermia, linfoma de células T cutâneo/ Síndrome de Sézary e doença enxerto-contra-hospedeiro após transplante de células-tronco hematopoiéticas. Tem sido empregada, ainda, com o intuito de induzir tolerância em transplantes de órgãos sólidos. O tratamento se baseia no efeito biológico de uma substância fotossensibilizante, o 8-metoxipsoraleno, e da radiação ultravioleta A, nas células mononucleares coletadas por aférese e reinfundidas ao paciente. $O$ mecanismo de ação parece ser devido à indução de imunidade anticlonotípica direcionada a clones patogênicos de células T. O tratamento induz a apoptose de células $T$ patogênicas, e a ativação de células apresentadoras de antígenos desempenha papel importante no processo imunomodulador. Rev. bras. hematol. hemoter. 2008; 30(2):153-161.

Palavras-chave: Fotoferese; doença-enxerto-contra hospedeiro; psoraleno; linfoma cutâneo.

\section{Introdução}

A fototerapia é reconhecida desde os primórdios da medicina. Os egípcios antigos reconheceram que a planta Ammi Majus, que crescia ao longo das margens do Nilo, aumentava o bronzeamento e a utilizaram no tratamento do vitiligo. ${ }^{1}$ Niels Fimsar ${ }^{1}$ recebeu o prêmio Nobel, em 1903, ao observar que lesões cutâneas de tuberculose freqüentemente melhoravam após exposição à luz ultravioleta (UV). Em 1940, Abdul El Mofty confirmou as observações de seus antecessores de que a ingestão de um preparado da planta Ammi Majus, em associação com a exposição à luz solar, era eficaz no tratamento do vitiligo. Na década de 1950, Lerner et al, reconheceram o 8-metoxipsoraleno(8-MOP) como princípio ativo da planta e que seu efeito terapêutico no vitiligo era obtido pela exposição à luz . ${ }^{2}$

Por volta dos anos 70 , vários estudos demonstraram que a irradiação cutânea com ultravioleta (UV) após a ingestão de 8-MOP era efetiva no tratamento da psoríase e sugeriram o nome PUVA (psoraleno + radiação ultravioleta A) para esta modalidade terapêutica. ${ }^{3}$ Simultaneamente, Gilchrest et al apresentaram bons resultados com a utilização do PUVA no tratamento do linfoma de células $T$ cutâneo. ${ }^{4}$ Edelson et al observaram em laboratório que linfócitos T eram sensíveis ao método PUVA, o que levou ao desenvolvimento de uma nova terapia denominada fotoferese extracorpórea (FEC), em que leucócitos eram removidos do paciente por aférese, tratados com 8-MOP e radiação ultravioleta $\mathrm{A}(\mathrm{UVA})$, e reinfundidos, em seguida, ao paciente. ${ }^{5,6} \mathrm{~A}$ eficácia da FEC no tratamento do linfoma cutâneo de células $\mathrm{T}(\mathrm{LCCT})^{5}$ associada a poucos efeitos adversos encorajou sua utilização em outras doenças mediadas por células T como: a doença enxerto-contra-hospedeiro $(\mathrm{DECH}){ }^{7}$ que ocorre após transplante alogênico de células-tronco hematopoiéticas, doenças auto-imunes (artrite reumatóide, ${ }^{8}$ esclerose sistêmica, ${ }^{9}$ lupus eritematoso sistêmico, ${ }^{10}$ pênfigo vulgar, ${ }^{11}$ psoríase artropática, ${ }^{12}$ dermatite atópica ${ }^{13} \mathrm{e}$ doença de $\mathrm{Crohn}^{14}$ ), além da utilização

${ }^{I}$ Doutora em Dermatologia pela Universidade Federal do Rio de Janeiro. Dermatologista do Centro de Transplante de Medula Óssea/Inca Rio de Janeiro-RJ.

${ }^{2}$ Mestre em Hematologia pela Universidade Federal do Rio de Janeiro. Diretor do Centro de Transplante de Medula Óssea/Inca - Rio de Janeiro-RJ.

Correspondência: Márcia de Matos Silva

Praça Cruz Vermelha 23-7 ${ }^{\circ}$ andar - Centro

20230-130 - Rio de Janeiro-RJ - Brasil

Tel: (21) 25066215; Fax:(21) 25092121

E-mail:matomarcia@gmail.com 
na prevenção de rejeição e indução de tolerância em transplantes de órgãos sólidos (coração, pulmão, ${ }^{15} \operatorname{rim}^{16}$ ) .

\section{Mecanismo de ação da fotoferese extracorpórea}

O impacto das radiações UVA e UVB no sistema imune é reconhecido. A radiação UVA é menos efetiva do que a UVB em danificar moléculas biológicas, como o DNA, e tem poucos efeitos diretos nas células devido à sua baixa energia. Sua efetividade biológica depende, assim, da presença de sensibilizantes, moléculas que absorvem a luz UV e indiretamente produzem efeitos biológicos. O fotossensibilizante mais utilizado na prática clínica é o 8-metoxipsoraleno (8-MOP), que tem ação fotobiológica quando ativado pela UVA-método PUVA. Ainda não está claro se o PUVA e o UVB têm efeitos imunológicos semelhantes. Ambos causam imunossupressão antígeno-específica e induzem a apoptose de células por dano ao DNA. Tendo como base o mecanismo fotobiológico do método PUVA, a FEC é utilizada quando se necessita de uma ação imunomoduladora (Figura 1).

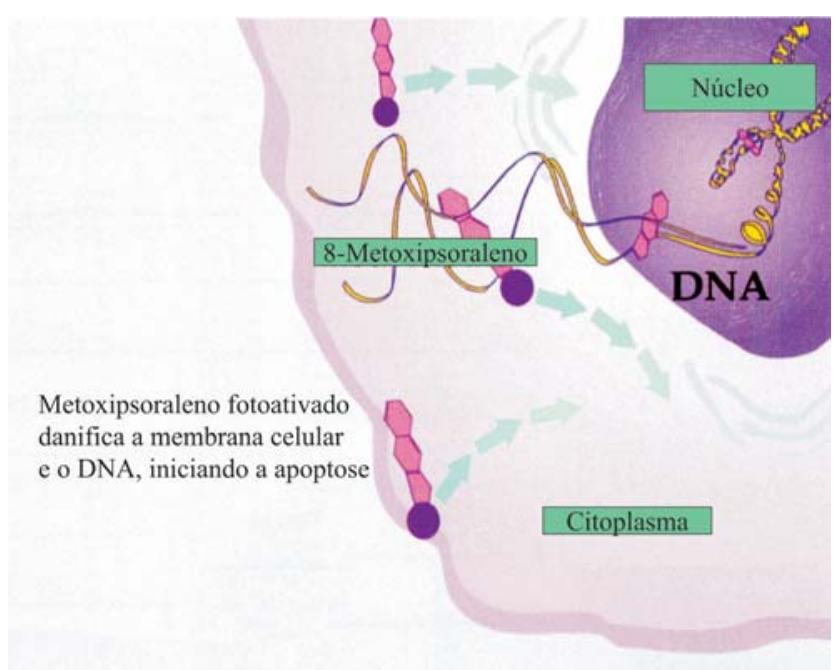

Figura 1. Mecanismo de ação FEC

Os efeitos específicos da FEC no sistema imune são atualmente foco de pesquisa em todo o mundo. ${ }^{17,18} \mathrm{Um}$ de seus aspectos mais intrigantes é a indução de dois efeitos aparentemente opostos: a ativação do sistema imune contra células neoplásicas e a repressão na expressão de clones em doenças auto-imunes (esclerose sistêmica, lupus eritematoso sistêmico e pênfigo vulgar) e em respostas imunes auto-alogênicas (DECH e rejeição em transplantes) (Tabela 1). Assim, é interessante observar que a FEC pode ter efeitos opostos, tolerogênico e estimulatório, em condições clínicas diferentes, através da interação entre linfócitos T apoptóticos e células dendríticas. Os mecanismos potenciais de indução de tolerância imune pela FEC incluem diminuição do estímulo ou depleção de células $\mathrm{T}$ efetoras, au-
Tabela 1. Fotoferese extracorpórea

Mecanismos de ação sugeridos

- Indução da apoptose de células T

- Ativação de monócitos seguida pela liberação de citocinas

- A combinação da apoptose de células T e ativação de monócitos leva a um efeito imunomodulador e a indução de imunidade anticlonotípica

mento da produção de citocinas antiinflamatórias ou diminuição de citocinas pró-inflamatórias, e geração de células T reguladoras..$^{19}$ Os modelos animais experimentais sugerem que a FEC induza a uma imunidade anticlonotípica. ${ }^{6,20}$ Com isso, o controle da doença seria mediado pela geração de células $\mathrm{T}$ supressoras clone-específicas desenvolvidas como resposta às células patogênicas modificadas pelo psoraleno e UVA. Perez et $a l^{21}$ apresentaram resultados semelhantes empregando um modelo de rejeição de aloenxerto cutâneo. Estes resultados indicam que, pelo menos a nível experimental, um processo de imunização ativa pode ocorrer após a administração de clones de células T singênicos fotoativados. O tratamento de leucócitos com 8-MOP e UVA leva à apoptose das células $\mathrm{T}$ em 48 horas. ${ }^{22-24} \mathrm{Em}$ contraste, macrófagos sangüíneos periféricos parecem comparativamente mais resistentes aos efeitos apoptóticos do 8-MOP e UVA. Estudos com citometria de fluxo revelam que as moléculas acessórias CD86 e moléculas de adesão CD36 são rapidamente estimuladas na superfície do macrófago após o término da FEC. Estes achados corroboram a observação de que macrófagos tratados com FEC exibem um aumento na habilidade de fagocitar células $\mathrm{T}$ apoptóticas. ${ }^{23}$ Portanto, pode-se sugerir que a fagocitose, o processamento e a apresentação de antígenos de células $\mathrm{T}$ apoptóticas (oriundos de clones de células $\mathrm{T}$ patogênicas), pelos macrófagos e células dendríticas, explicariam a indução da imunidade anticlonotípica pela $\mathrm{FEC},{ }^{25}$ conferindo ação prolongada ao trata (Figura 2).

\section{FEC - Procedimento}

A realização da FEC implica exposição extracorpórea de células mononucleares sangüíneas periféricas obtidas por aférese ao 8-MOP, fotoativação com radiação UVA e subseqüente reinfusão ao paciente (Figura 3). O procedimento é feito através de equipamento específico (o mais utilizado é o sistema UVAR®-Therakos, Westchester, PA, USA) em três etapas: a primeira é a coleta de células periféricas mononucleares. Nesta etapa, mudanças no ambiente celular, como diminuição da temperatura, efeito da centrifugação, mudanças na forma das células e modificação do $\mathrm{pH}$, podem estar relacionados com o aumento da ativação dos monócitos e possivelmente com a indução da diferenciação de células dendríticas. ${ }^{26}$ 


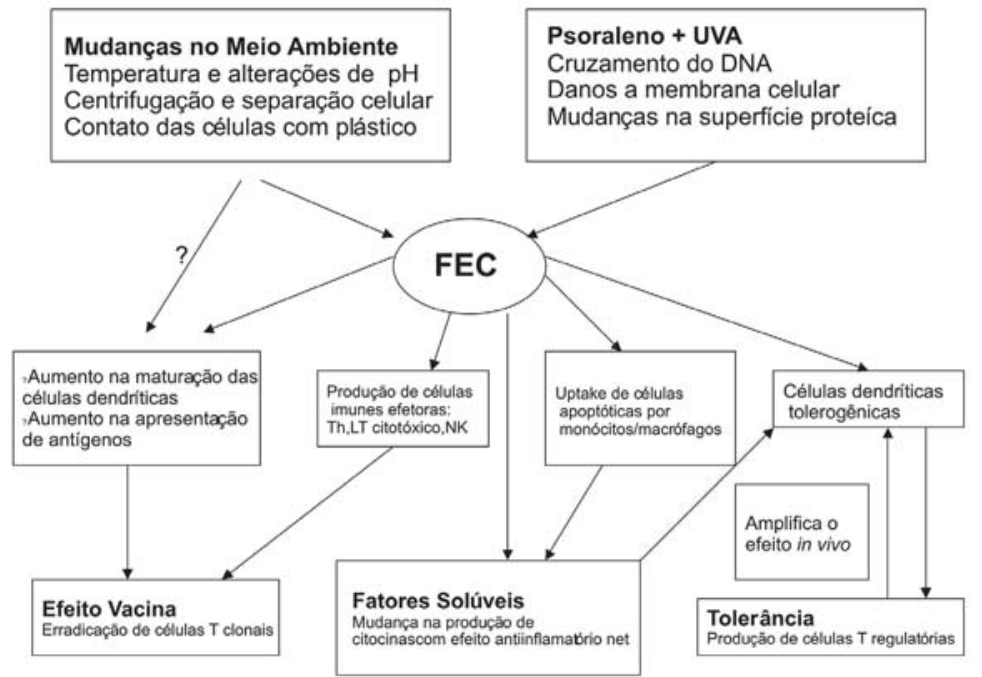

Figura 2. Mecanismo de Ação proposto para FEC

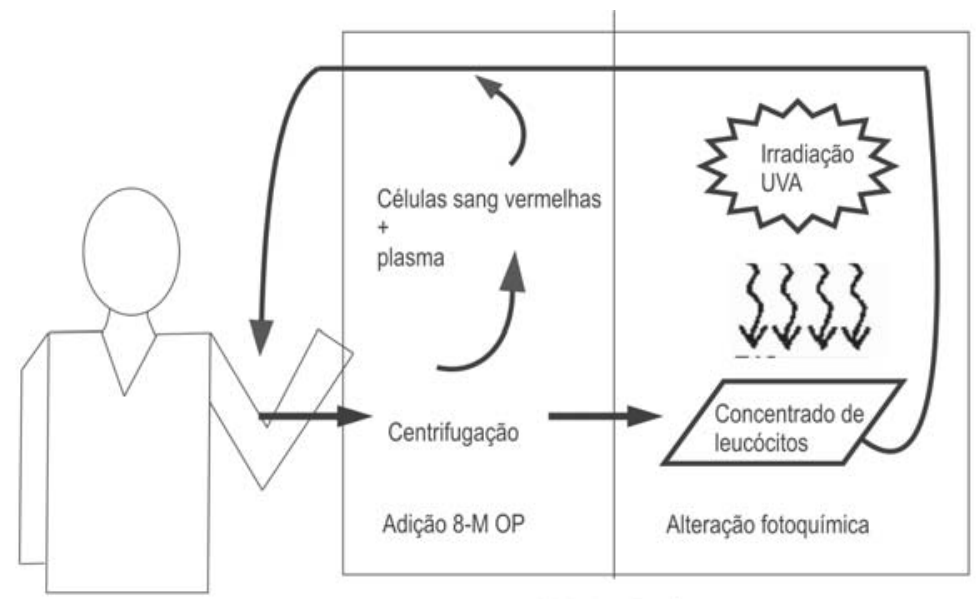

Máquina Fotoferese

Figura 3. Procedimento da FEC

Na segunda etapa, $300 \mathrm{~mL}$ de plasma são coletados e o 8-MOP (metoxalen líquido-UVADEX®) é administrado diretamente em aproximadamente $240 \mathrm{~mL}$ de concentrado de leucócitos, o que evita os efeitos indesejáveis de intolerância gástrica e a incerteza quanto à sua absorção oral. A dose de metoxalen líquido é calculada de acordo com a seguinte fórmula: volume coletado no tratamento $\mathrm{x} 0,017=$ mililitros de 8-MOP. O concentrado de leucócitos passa por uma câmara estéril (câmara de fotoativação) com $1 \mathrm{~mm}$ de espessura, e é irradiado com UVA, com exposição dos leucócitos a 2 $\mathrm{Jcm}^{2}$. Nesta etapa ocorrem dano da membrana celular e modificações antigênicas da membrana, intercalamento ao DNA e ligação a várias proteínas, culminando com a apoptose dos linfócitos e ativação das células apresentadoras de antígenos.

A terceira etapa é a reinfusão das células tratadas ao paciente. $\mathrm{O}$ tratamento pode ser realizado por um a dois dias, em intervalos de 2-4 semanas, na dependência da doença de base.

\section{Indicações da FEC}

\section{Linfomas de células $T$}

O linfoma cutâneo de células T (LCCT) é uma doença maligna de origem linfóide clonal de linfócitos T helper e, em geral, tem evolução lenta. Os sinais iniciais freqüentemente aparecem na pele como placas eritematosas, que podem evoluir para tumores e eritrodermia. O envolvimento da medula óssea e de células características no sangue periférico (células de Sézary) são freqüentemente acompanhados por eritrodermia esfoliativa-Síndrome de Sézary (SS). Atualmente, utiliza-se o PUVA como terapia de primeira linha para formas clínicas mais leves. Entretanto, para estágios avançados de LCCT e SS, a resposta não é satisfatória. A quimioterapia pode ser utilizada, embora esteja associada com aumento da morbidade. O primeiro tratamento da SS com FEC foi conduzido por Edelson et al. ${ }^{5}$ Seu objetivo era destruir a maior quantidade possível de células sangüíneas de LCCT por apoptose. Edelson observou, entretanto, que, paralelamente à eliminação de células fototratadas no sangue, o número de células malignas não-tratadas diminuía consideravelmente na pele e nos linfonodos, o que sugeria uma ação antitumoral sistêmica, com indução de células CD8+ tumor-específicas. Assim, a indução de apoptose de células tumorais circulantes parece tornar as células dendríticas apresentadoras de antígenos, contendo antígenos tumorais processados, capazes de induzir uma resposta imune antitumoral (Figura4). A partir de então, vários estudos na literatura demonstraram bons resultados no tratamento de LCCT refratários, avançados, com FEC27-28, sendo esta a primeira indicação aprovada pelo FDA desde 1988. Devido às variações na seleção de pacientes e protocolos de tratamento, foram estabelecidos alguns critérios para o tratamento de LCCT com FEC: 1. doença de evolução curta (menos de 2 anos); 2 . quantidade reduzida de células de Sézary no sangue periférico (10\%-20\% células mononucleares); 3 . número normal de linfócitos T citotóxicos; 4 . atividade de células natural killer normal; 5. ausência de tratamento quimioterápico intenso prévio; 6. ausência de adenopatia volumosa ou doença visceral.

\section{Doenças auto-imunes}

A eficácia do tratamento com FEC das doenças autoimunes com alterações cutâneas tem sido estudada, mas, após décadas de interesse, relatos múltiplos de casos, protocolos abertos e um estudo controlado, seu papel ainda precisa ser melhor estabelecido. Na esclerodermia, a identificação de 


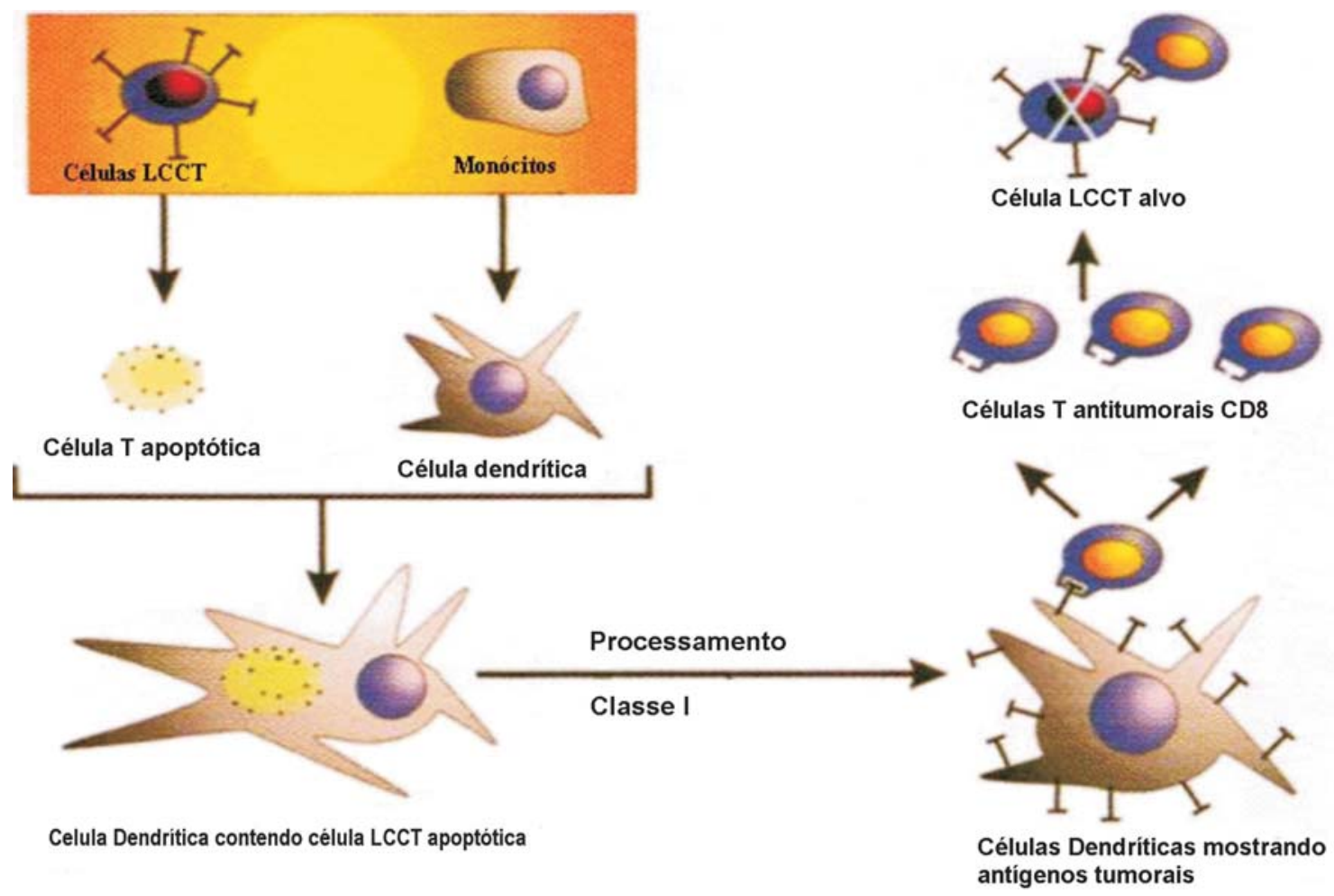

Figura 4. Mecanismos de ação propostos no LCCT: apoptose e maturação de células dendríticas. (Adaptado de Foss FM. 2007 BMT Meeting-Keystone).

clones de células-T auto-reativos mostra um mecanismo de ação parecido com o observado nos LCCT. Reinisch et al ${ }^{29}$ observaram um efeito poupador de corticóide em pacientes portadores de Doença de Crohn, com alojamento dos leucócitos submetidos a FEC especificamente no intestino, em lesões da mucosa do cólon. Rook et $a l^{30}$ trataram quatro pacientes com pênfigo vulgar com redução da IgG e redução significativa do uso de corticóides e imunossupressores.

\section{Rejeição a transplantes de órgãos sólidos}

Estudos preliminares demonstraram que a FEC é efetiva no tratamento da rejeição a transplantes de órgãos sólidos, especialmente o transplante cardíaco e de pulmão.

\section{Doença Enxerto-Contra-Hospedeiro}

A doença enxerto-contra-hospedeiro $(\mathrm{DECH})$ refratária a esteróides é uma complicação, de difícil manuseio, do transplante alogênico de células-tronco hematopoiéticas. Aproximadamente $30 \%-50 \%$ dos pacientes com DECH crônica têm doença extensa, o que requer o uso de imunossupressores em altas doses por longo tempo, aumentando as complicações infecciosas e os índices de mortalidade. ${ }^{31}$ Assim, novas estratégias terapêuticas, como a FEC, têm sido utilizadas tanto na forma aguda como crônica da DECH pelo seu potencial de controlar a doença, reduzindo a utilização de corticoterapia sistêmica em mais de 50\% dos pacientes ${ }^{32,33,34}$ (Tabela 2).
As respostas clínicas da FEC foram inicialmente demonstradas por Rosetti et al, que observaram um efeito seletivo da FEC nas células T CD8+ efetoras citotóxicas sem mudanças nas populações CD4+ T-helper em cinco crianças com DECH crônica, sugerindo um efeito diferente nos grupos de células T. ${ }^{35}$ Recentes estudos sugerem que pacientes com DECH responsiva a FEC apresentam sobrevida maior do que os não-responsivos, ${ }^{34,36}$ o que possivelmente está relacionado à redução do uso de corticoterapia. ${ }^{34}$ Os relatos de eficácia da FEC em DECH visceral ainda não são consistentes.

Durante a FEC, aproximadamente 500 milhões de células apoptóticas são reinfundidas ao paciente. Existem evidências crescentes de que o material derivado das células

Tabela 2. FEC como terapia de segunda linha para DECH crônica

\begin{tabular}{lcl}
\hline Autor & $\begin{array}{c}\text { No. de } \\
\text { Pacientes }\end{array}$ & \multicolumn{1}{c}{ Referências } \\
\hline Greinix et al & 15 & Blood 1998;92:3098 \\
Apisarnthanarax et al & 32 & BMT 2003;31:459 \\
Seaton et al & 28 & Blood 2003;102;1217 \\
Foss et al & 25 & BMT 2005; 35:1187 \\
Rubegni et al & 27 & Br J Hematol 2005;130: 271 \\
Couriel et al & 71 & Blood 2006;107;3074 \\
\hline
\end{tabular}




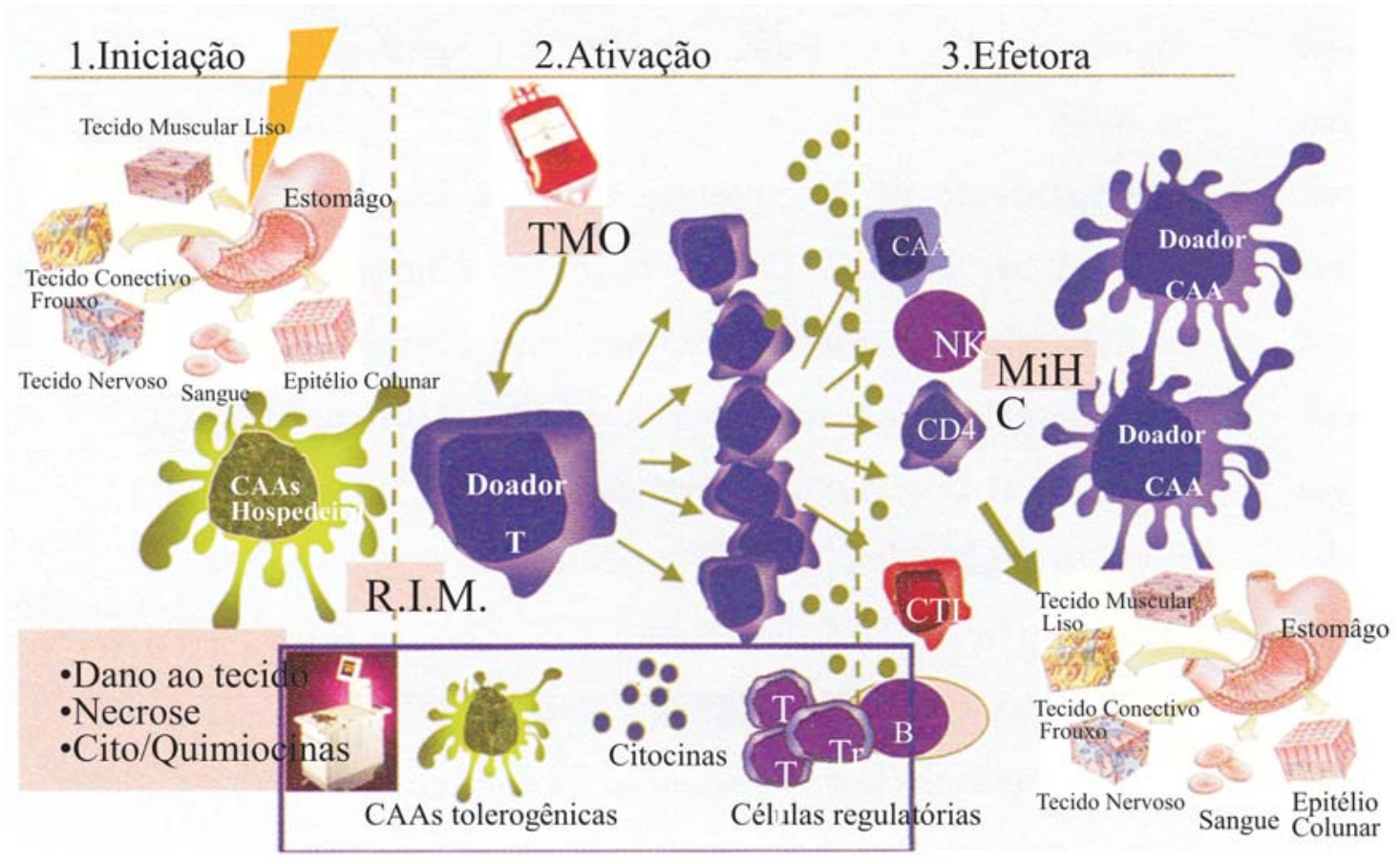

Figura 5. Patogênese da DECH

apoptóticas, uma vez fagocitado, module ativamente o sistema imune, com conseqüente ativação de células dendríticas, as quais apresentam os antígenos derivados de células apoptóticas, estimulando linfócitos $\mathrm{T}$ citotóxicos CD8+. Este fato, em pacientes com DECH crônica, aumenta a produção de citocinas imunossupressoras tal como receptores antagonistas de IL-10 e IL-1 pelos macrófagos e monócitos, levando a anergia de células T periféricas ${ }^{37}$ (Figura 5).

Portanto, provavelmente como conseqüência de apoptose, uma variedade de antígenos nas células tratadas entra em contato com células dendríticas fagocitantes ativas, modulando a resposta imune e promovendo efeito estimulatório ou tolerogênico (Tabela 3). No entanto, não se pode dizer se estes mecanismos agem em conjunto, ou de forma e graus diferenciados ou, ainda, que a resposta clínica à FEC seja resultado do predomínio de um ou de outro, ou de vários mecanismos agindo na mesma direção. Parece, assim, que o efeito da FEC seja simplesmente o de restaurar a homeostase imunológica (Figura 6).

A combinação da FEC com terapias imunossupressoras tradicionais para tratar $\mathrm{DECH}$ pode permitir a redução dos fármacos utilizados e sua toxicidade associada (particularmente esteróides).

Mais de uma década de experiência clínica tem demonstrado que a FEC é bem tolerada, sem evidências de imunossupressão sistêmica. As indicações de consenso para inclusão de pacientes para FEC são: DECH não responsiva ao tratamento convencional, tratamento não concomitante com globulina antitimócito ou anticorpos anticlonais.
Tabela 3. Alterações celulares/citocinas na DECH após a FEC

Linfócitos

Apoptose

Diminuição de células Th1 secretoras de IFN- $\gamma$

Aumento de células Th2 secretoras de IL-4 e IL-10

Restauração do balanço Th1/Th2 através de Th2

Diminuição do receptor I TNF- $\alpha$ solúvel e receptor $\alpha$ solúvel de IL-2

Indução de grupos de células T reguladoras que sintetizam IL-10 Normalização das taxas CD4/CD8

Diminuição de linfócitos CD8

\section{Monócitos}

Sem apoptose

Sem mudanças na produção de TNF- $\alpha$

Aumento na síntese de receptores antagonistas de IL-10 e IL-1Ra

Diferenciação de células dendríticas CD83+ imaturas que

fagocitam células apoptóticas

Células Dendríticas(CD)

Diminuição da população de CD1 monocitóides(CD 80+ CD 123+) Aumento da população de CD2 plasmocitóides(CD83+ CD 86+)

Restauração do balanço CD1/CD2 em favor da população CD2

\section{Células Natural Killer}

Aumento no número de células natural killer CD3+ CD56+ 


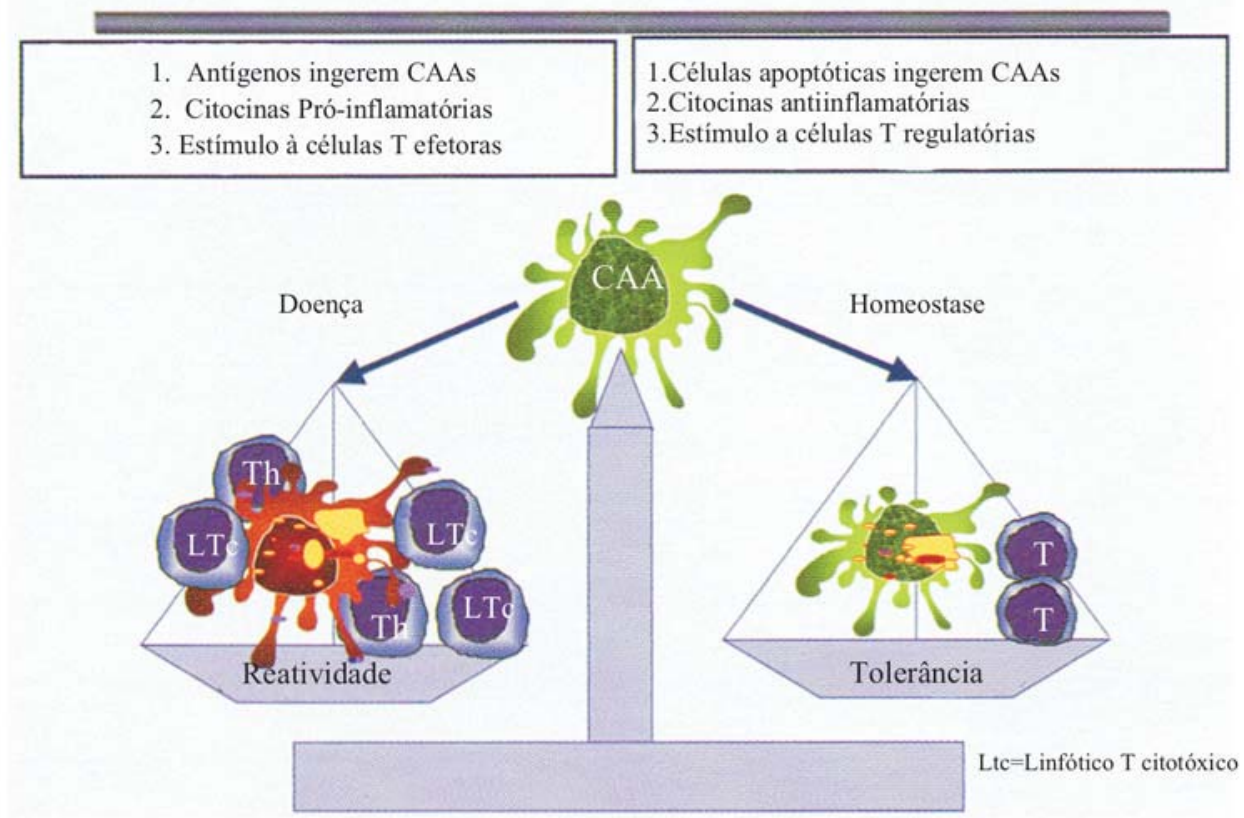

Figura 6. Células apresentadoras de antígenos (CAAs) decidem o destino da resposta imune (Adaptado de Foss FM. 2007 BMT MeetingKeystone)

\section{FEC na DECH aguda}

Os relatos da utilização de FEC no tratamento da DECH aguda são menos freqüentes e promissores do que nas formas crônicas da doença. ${ }^{38-41}$ As melhores respostas são observadas quando a terapia é iniciada precocemente e em casos menos graves de $\mathrm{DECH}^{42}$ (Figuras 7 e 8 ).

Greinix et al $^{42}$ trataram 21 pacientes com DECH aguda refratária a esteróides de grau II a IV. A resposta completa na pele foi alcançada em $60 \%$ dos pacientes (100\% grau II, $67 \%$ grau III e $12 \%$ grau IV), no fígado em $67 \%$, mas não observaram boa resposta para $\mathrm{DECH}$ aguda intestinal. A taxa de sobrevida foi de 57\% em 25 meses de acompanhamento. Numa avaliação com maior número de casos, Greinix et $a l^{43}$ trataram 59 pacientes com DECH aguda obtendo resposta completa $(\mathrm{RC})$ em $82 \%$ de pacientes com envolvimento cutâneo, $61 \%$ com alterações hepáticas e $61 \%$ intestinal. A $\mathrm{RC}$ foi obtida em $86 \%$ dos pacientes com DECH aguda grau II, 55\% grau III e 30\% grau IV. Messina et a ${ }^{36}$ trataram com FEC 33 crianças com DECH aguda refratária. As respostas foram boas em todos os órgãos, incluindo pele (76\%), fígado $(60 \%)$ e trato gastrintestinal $(75 \%)$.

No caso da DECH aguda, Greinix sugere a realização de estudos utilizando a FEC como terapia de primeira ou segunda linha, com intuito de reduzir a duração e dose de esteróides em pacientes com alto risco para desenvolver infecções oportunistas e que a administração da FEC seja introduzida precocemente. $^{44}$

\section{FEC na DECH crônica}

A eficácia do PUVA no tratamento de pacientes com

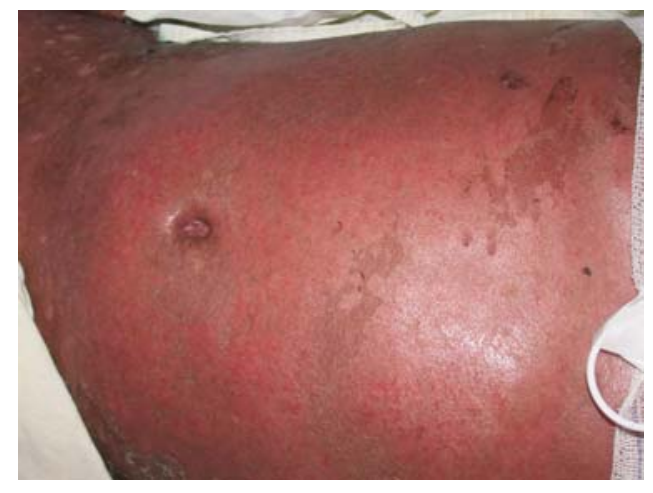

Antes da FEC

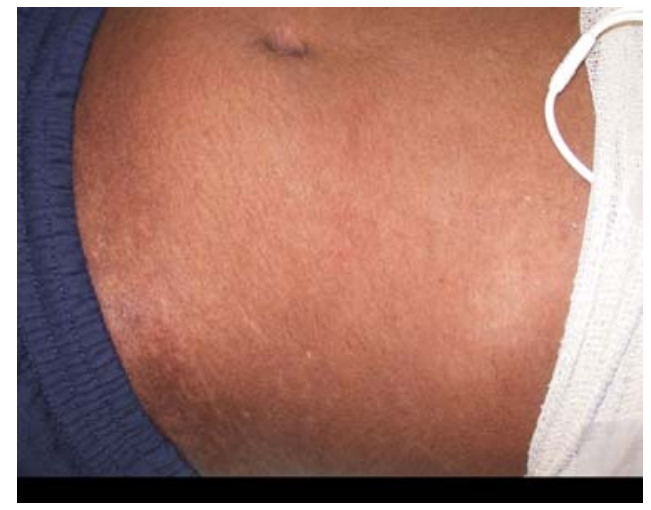

Depois de oito sessões de FEC

Figuras 7 e 8. DECH aguda - antes e depois da FEC

manifestações cutâneas de DECH crônica ${ }^{45,46}$ e a demonstração de que a radiação UV afeta diretamente o número de células de Langerhans ou as células apresentadoras de 


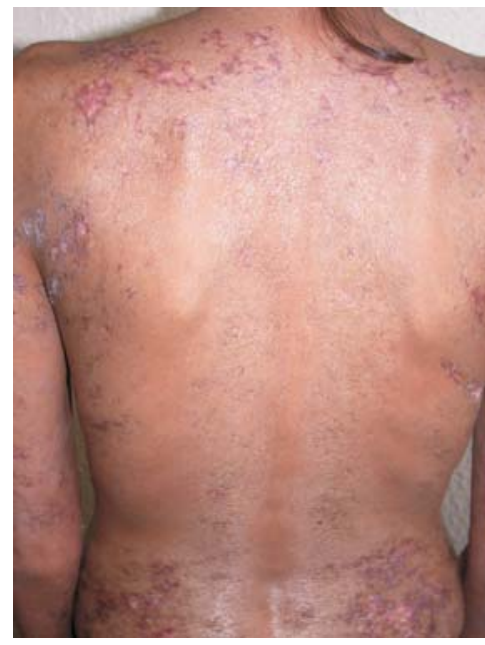

Antes da FEC

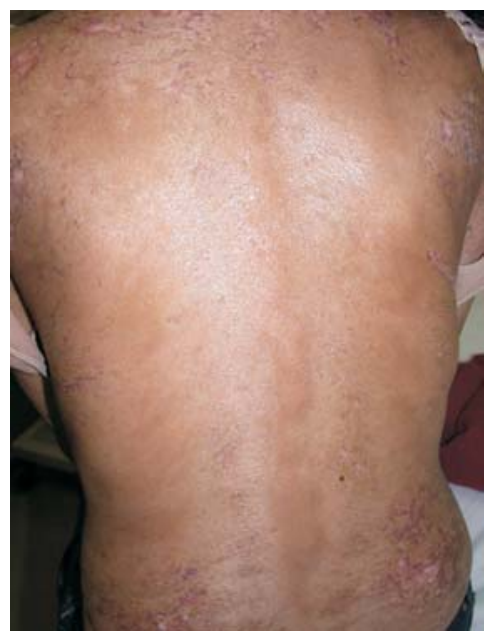

Depois de vinte sessões de FEC

Figuras 9 e 10. DECH crônica - antes e depois da FEC

antígenos na epiderme estimularam a realização de vários estudos com o intuito de explorar a eficácia da FEC em pacientes portadores de DECH crônica refratária a imunossupressores $^{7,47,48}$ (Figuras 9 e 10). Greinix et a ${ }^{49}$ apresentaram taxas de resposta em torno de $90 \%$ com FEC para DECH com manifestação cutânea, e bons resultados em pacientes com envolvimento da mucosa oral. Sua utilização em manifestações de DECH pulmonar ou hepática, entretanto, não tiveram a mesma resposta.

Embora os resultados de estudos randomizados ainda não estejam disponíveis, uma resposta cutânea em torno de $75 \%$ (35\% de resposta completa) é relatada em pacientes tratados com FEC. DECH crônica hepática, pulmonar e com manifestações orais parecem apresentar resposta menor. ${ }^{50} \mathrm{O}$ êxito da resposta parece estar relacionado à associação da FEC logo após o início da doença.

As principais dificuldades para avaliação da eficácia clínica nos estudos publicados são: heterogeneidade dos pacientes tratados, especialmente com doença crônica, devido a não concordância da definição de $\mathrm{DECH}$ não-responsiva; grande variabilidade no tempo entre o início da doença e o início da FEC; protocolos e esquemas de tratamento diferentes; heterogeneidade do tratamento imunossupressor concomitante..$^{51}$

\section{Eventos adversos da FEC}

Em geral, o tratamento com FEC é bem tolerado e está associado a mínimos eventos adversos. Um problema comum é a necessidade, para a aférese, de acesso venoso central com cateter, em pacientes sem acesso venoso periférico, nos quais as freqüentes obstruções e complicações infecciosas podem levar à interrupção do tratamento. A aférese extracorpórea pode levar à hipotensão, que raramente é sintomática, e febre, após a reinfusão, às vezes é observada. Nenhum sinal de toxicidade ao citrato ou complicações metabólicas foi descrito até o momento. A fotofobia durante o procedimento pode acontecer. A queda de hematócrito e hemoglobina constitui efeito freqüente e transitório.

\section{Considerações finais}

A FEC é uma terapia imunomodulatória relativamente segura, baseada na aférese de células sensíveis à luz. Em muitas instituições a FEC é utilizada, associada ou não a outros modificadores da resposta biológica, como tratamento de escolha na SS. Os estudos futuros devem levar em consideração o início do tratamento com FEC na fase inicial da DECH. Os poucos efeitos adversos tornam a FEC mais atrativa do que o uso de quimioterápicos e imunossupressores e tem estimulado a utilização da FEC por longos períodos. Devido ao custo do material descartável utilizado e do equipamento, a FEC é um procedimento caro. Entretanto, estes custos são compensados pela redução da terapia imunossupressora influindo diretamente na hospitalização, qualidade de vida dos pacientes e mortalidade relacionada à doença de base e seu tratamento. A boa resposta clínica no tratamento de doenças mediadas por células $\mathrm{T}$ vem estimulando sua utilização em outras doenças além das descritas acima, demonstrando o grande potencial terapêutico e em pesquisa, deste procedimento.

\footnotetext{
Abstract

Extracorporeal photopheresis is a method of cell therapy that has demonstrated efficacy in autoimmune diseases, cutaneous T-cell lymphoma/Sézary syndrome and graft-versus-host disease after hematopoietic stem-cell transplantation. This technique has also been employed as a treatment strategy to induce tolerance after solid organ transplants. Treatment is based on the biological effect of ultraviolet A radiation and a photosensitizing drug, 8methoxypsoralen, on mononuclear cells collected by apheresis and reinfused into the patient. The suggested mechanism of action is related to the induction of anticlonotypic immunity directed against pathogenic clones of Tlymphocytes. Treatment induces apoptosis of
} 
pathogenic T-cells, and it appears that activation of antigenpresenting cells has an important role in this process. Rev. bras. hematol. hemoter. 2008; 30(2):153-161.

Key words: Photopheresis; graft-versus-host disease; psoralens; cutaneous lymphoma.

\section{Referências Bibliográficas}

1. Fitzpatrick TB, Pathak MA. Historical aspects of methoxsalen and other furocoumarins. J Invest Dermatol. 1959;32(2, Part 2):229-31

2. Lerner AB, Denton CR, Fitzpatrick TB. Clinical and experimental studies with 8-methoxypsoralen in vitiligo. J Invest Dermatol. 1953;20(4):299-314

3. Parrish JA, Fitzpatrick TB, Tanenbaum L, Pathak MA. Photochemotherapy of psoriasis with oral methoxsalen and longwave ultraviolet light. N Eng1 J Med. 1974;291(23):1207-11.

4. Gilchrest BA, Parrish JA, Tanenbaum L, et al. Oral methoxsalen photochemotherapy of mycosis fungoides. Cancer. 1976;38 (2): 683-9.

5. Edelson R, Berger C, Gasparro F, et al. Treatment of cutaneous Tcell lymphoma by extracorporeal photochemotherapy. Preliminary results. N Engl J Med. 1987;316(6):297-303.

6. Heald PW, Edelson RL. Photopheresis for T cell mediated diseases. Adv Dermatol. 1988;3:25-40.

7. Child FJ, Ratnavel R, Watkins P, et al. Extracorporeal photopheresis (ECP) in the treatment of chronic graft-versus-host disease (GVHD). Bone Marrow Transplant. 1999;23(9):881-7.

8. Menkes CJ, Andreu G, Heshmati F, Hilliquin P. Extracorporeal photochemotherapy. Br J Rheumatol. 1992;31(11):789-90.

9. Rook AH, Freundlich B, Jegasothy BV, et al. Treatment of systemic sclerosis with extracorporeal photochemotherapy. Results of a multicenter trial. Arch Dermatol. 1992;128(3):337-46.

10. Knobler RM. Extracorporeal photochemotherapy for the treatment of lupus erythematosus: preliminary observations. Springer Semin Immunopathol. 1994;16(2-3):323-5.

11. Rook AH, Jegasothy BV, Heald P, et al. Extracorporeal photochemotherapy for drug-resistant pemphigus vulgaris. Ann Intern Med. 1990;112(4):303-5.

12. de Misa RF, Azaña JM, Harto A, Ledo A. Extracorporeal photochemotherapy in the treatment of severe psoriatic arthropathy. Br J Dermatol. 1992;127(4):448.

13. Prinz B, Nachbar F, Plewig G. Treatment of severe atopic dermatitis with extracorporeal photopheresis. Arch Dermatol Res. 1994; 287(1):48-52.

14. Guariso G, D'Incà R, Sturniolo GC, Zancan L, Dall'Amico R. Photopheresis treatment in severe Crohn disease. J Pediatr Gastroenterol Nutr. 2003;37(4):517-20.

15. Andreu G, Achkar A, Couetil JP, et al. Extracorporeal photochemotherapy treatment for acute lung rejection episode. J Heart Lung Transplant. 1995;14(4):793-6.

16. Horina JH, Müllegger RR, Horn S, et al. Photopheresis for renal allograft rejection. Lancet. 1995;346(8966):61.

17. Moyal D. Immunosuppression induced by chronic ultraviolet irradiation in humans and its prevention by sunscreens. Eur $\mathrm{J}$ Dermatol. 1998;8(3):209-11.

18. Nghiem DX, Kazimi N, Clydesdale G, Ananthaswamy HN, Kripke ML, Ullrich SE. Ultraviolet a radiation suppresses an established immune response: implications for sunscreen design. J Invest Dermatol. 2001;117(5):1193-9.
19. Peritt D. Potential mechanisms of photopheresis in hematopoietic stem cell transplantation. Biol Blood Marrow Transplant. 2006; 12(1 Suppl 2):7-12.

20. Ben-Nun A, Wekerle H, Cohen IR. Vaccination against autoimmune encephalomyelitis with T-lymphocyte line cells reactive against myelin basic protein. Nature. 1981;292(5818):60-1.

21. Perez M, Edelson R, Laroche L, Berger C .Inhibition of antiskin allograft immunity by infusions with syngeneic photoinactivated effector lymphocytes. J Invest Dermatol. 1989;92(5):669-76.

22. Bladon J, Taylor PC. Extracorporeal photopheresis induces apoptosis in the lymphocytes of cutaneous T-cell lymphoma and graftversus-host disease patients. Br J Haematol. 1999; 107(4):707-11.

23. Yoo EK, Rook AH, Elenitsas R, Gasparro FP, Vowels BR. Apoptosis induction of ultraviolet light $\mathrm{A}$ and photochemotherapy in cutaneous T-cell Lymphoma: relevance to mechanism of therapeutic action. J Invest Dermatol. 1996;107(2):235-42.

24. Enomoto DN, Schellekens PT, Yong SL, et al.Extracorporeal photochemotherapy (photopheresis) induces apoptosis in lymphocytes: a possible mechanism of action of PUVA therapy. Photochem Photobiol. 1997;65(1):177-80.

25. Albert ML, Sauter B, Bhardwaj N. Dendritic cells acquire antigen from apoptotic cells and induce classI-restricted CTLs. Nature. 1998;392(6671):86-9.

26. Edelson RL. Transimmunization: the science catches up to the clinical success. Transfus Apher Sci. 2002;26(3):177-80.

27. Gottlieb SL, Wolfe JT, Fox FE, et al.Treatment of cutaneous Tcell lymphoma with extracorporeal photopheresis monotherapy and in combination with recombinant interferon alfa: a 10-year experience at a single institution. J Am Acad Dermatol. 1996; 35(6):946-57.

28. Duvic M, Hester JP, Lemak NA. Photopheresis therapy for cutaneous T-cell lymphoma. J Am Acad Dermatol. 1996;35(4):573-9.

29. Reinisch W, Nahavandi H, Santella R, et al. Extracorporeal photochemotherapy in patients with steroid-dependent Crohn's disease: a prospective pilot study. Aliment Pharmacol Ther. 2001;15(9):1313-22.

30. Rook AH, Jegasothy BV, Heald P, et al. Extracorporeal photochemotherapy for drug-resistant pemphigus vulgaris. Ann Intern Med. 1990;112(4):303-5.

31. Bhushan V, Collins RH Jr. Chronic graft-vs-host disease. JAMA. 2003;290(19):2599-603.

32. Apisarnthanarax N, Donato M, Körbling M, et al.Extracorporeal photopheresis therapy in the management of steroid-refractory or steroid-dependent cutaneous chronic graft-versus-host disease after allogeneic stem cell transplantation: feasibility and results. Bone Marrow Transplant. 2003;31(6):459-65.

33. Seaton ED, Szydlo RM, Kanfer E, et al. Influence of extracorporeal photopheresis on clinical and laboratory parameters in chronic graft-versus-host disease and analysis of predictors of response. Blood. 2003;102(4):1217-23.

34. Foss FM, DiVenuti GM, Chin K, et al. Prospective study of extracorporeal photopheresis in steroid-refractory or steroidresistant extensive chronic graft-versus-host disease: analysis of response and survival incorporating prognostic factors. Bone Marrow Transplant. 2005;35(12):1187-93.

35. Rossetti F, Dall'Amico R, Crovetti G, et al. Extracorporeal photochemotherapy for the treatment of graft-versus-host disease. Bone Marrow Transplant. 1996;18 (Suppl 2):175-81.

36. Messina C, Locatelli F, Lanino E, et al. Extracorporeal photochemotherapy for paediatric patients with graft-versus-host disease after haematopoietic stem cell transplantation. Br J Haematol. $2003 ; 122(1): 118-27$. 
37. Berger CL, Hanlon D, Kanada D, et al. Transimmunization, a novel approach for tumor immunotherapy. Transfus Apher Sci. 2002;26(3):205-16.

38. Besnier DP, Chabannes D, Mahé B, et al. Treatment of graftversus-host disease by extracorporeal photochemotherapy: a pilot study. Transplantation. 1997;64(1):49-54.

39. Smith EP, Sniecinski I, Dagis AC, et al. Extracorporeal photochemotherapy for treatment of drug-resistant graft-vs.-host disease. Biol Blood Marrow Transplant. 1998;4(1):27-37.

40. Richter HI, Stege H, Ruzicka T, et al.Extracorporeal photopheresis in the treatment of acute graft-versus-host disease. J Am Acad Dermatol. 1997;36(5 Pt 1):787-9.

41. Dall'Amico R, Zacchello G. Treatment of graft-versus-host disease with photopheresis. Transplantation. 1998;65(9):1283-4.

42. Greinix HT, Volc-Platzer B, Kalhs P, et al. Extracorporeal photochemotherapy in the treatment of severe steroid-refractory acute graft-versus-host disease: a pilot study. Blood. 2000; 96 (7):2426-31

43. Greinix HT, Knobler RM, Worel N, et al. The effect of intensified extracorporeal photochemotherapy on long-term survival in patients with severe acute graft-versus-host disease. Haematologica. 2006;91(3):405-8.

44. Greinix HT, Socié G, Bacigalupo A, et al. Assessing the potential role of photopheresis in hematopoietic stem cell transplant. Bone Marrow Transplant. 2006;38(4):265-73

45. Vogelsang GB, Wolff D, Altomonte V, et al. Treatment of chronic graft-versus-host disease with ultraviolet irradiation and psoralen (PUVA).Bone Marrow Transplant. 1996;17(6):1061-7.
46. Atkinson K, Weller P, Ryman W, Biggs J. PUVA therapy for drugresistant graft-versus-host disease. Bone Marrow Transplant. $1986 ; 1(2): 227-36$.

47. Spisek R, Gasova Z, Bartunkova J. Maturation state of dendritic cells during the extracorporeal photopheresis and its relevance for the treatment of chronic graft-versus-host disease.Transfusion. 2006;46(1):55-65.

48. Bisaccia E, Palangio M, Gonzalez J, et al. Treating refractory chronic graft-versus-host disease with extracorporeal photochemotherapy.Bone Marrow Transplant. 2003;31(4):291-4.

49. Greinix HT, Volc-Platzer B, Knobler RM. Extracorporeal photochemotherapy in the treatment of severe graft-versus-host disease. Leuk Lymphoma. 2000;36(5-6):425-34.

50. Ratanatharathorn V, Ayash L, Lazarus HM, Fu J, Uberti JP. Chronic graft-versus-host disease: clinical manifestation and therapy. Bone Marrow Transplant. 2001;28(2):121-9.

51. Marshall SR. Technology insight: ECP for the treatment of GvHD - can we offer selective immune control without generalized immunosuppression? Nat Clin Pract Oncol. 2006;3(6):302-14.

Avaliação: Editor e dois revisores externos

Conflito de interesse: sem conflito de interesse

Recebido: 21/05/2007

Aceito: 21/09/2007 